\title{
Qi Business Culture and the Cultivation of Financial Professionals in Higher Vocational Institute
}

\author{
Hua Yang ${ }^{*}$, Zhe $\mathrm{Xu}^{2}$, Wenxin Ju${ }^{1}$ \\ ${ }^{1}$ Accounting College, ZiBo Vocational Institute, Zibo 255400, Shandong Province, China \\ ${ }^{2}$ Human Resources Office, ZiBo Vocational Institute, Zibo 255400, Shandong Province, China \\ *Corresponding author: Hua Yang, yangh218@163.com
}

\begin{abstract}
This paper combs the rise and development process of Qi business and Qi business culture, and concludes that Qi business culture has such spiritual connotations as pragmatism, openness, integrity, innovation, self-improvement and flexibility. It is not only a part of Chinese excellent traditional culture, but also has important time value for today's commercial and trade activities and the cultivation of financial professionals, it can be used to guide the training of finance and economics professionals in higher vocational institute, establish the curriculum system of professional innovation integration, cultural penetration, progressive level and the hybrid teaching mode of matrix theory and practice integration, so as to cultivate outstanding technical and skilled talents of finance and economics major.
\end{abstract}

Keywords: Qi business culture; Higher vocational institute; Major in finance and economics; Personnel training

Publication date: August 2021; Online publication: August 30, 2021

\section{Introduction}

Qi culture originated in Jiang Taigong, spread to Guan Zhong and formed a system, and then further developed by Jixia Qi legalists. At the beginning of the founding of Qi Dynasty, Jiang Taigong adopted the economic policy of opening up to other countries, that is, attaching equal importance to agriculture, industry and commerce, and developing diversified economy. He gradually made the country rich, the people strong, and the culture prosperous, which made Qi rapidly develop from a remote and poor country to a powerful country in the east. Guan Zhong lived in an era of the rise of princes, hegemony, social upheaval and profound change. With the courage of businessmen and the wisdom of thinkers, he had an insight into the social development trend of the separation and annexation of various countries, had a grand political ambition of creating hegemony, and had a profound sense of righteousness. He assisted Qi Huan Gong in politics for more than ten years, and worked hard for governance and reform, it makes the backward state of Qi rise rapidly and occupy the top position of the five hegemonic powers. It applies the business strategy of seeking advantages and avoiding disadvantages to politics and achieves brilliant success. Therefore, Qi business culture is an important part of Qi culture. It is not only one of the main sources of Chinese traditional culture, but also an important part of it. Its characteristics of reform, openness, pluralism and pragmatism determine that it contains rich spirit of inheritance, enterprising, people-oriented, compatibility and responsibility, which is still of positive value today. It is not only suitable for modern commercial trade and business environment, but also the necessary professional quality and ideological quality for today's financial professionals, it can be integrated into the training of financial professionals in higher vocational institute through the appropriate path. 


\section{Journals reviewed}

Scholars at home and abroad, such as Wang Zhimin (2017), mostly focus on the economic thoughts of their representatives (Jiang Taigong and Guan Zhong), and lack the research on the inheritance and application of Qi business culture in today's society, especially the integration of this excellent traditional culture into the cultivation of financial professionals in higher vocational Institute.

In recent years, domestic scholars have begun to pay attention to the research on the integration of traditional culture into the talent training mode of Finance and economics major in higher vocational Institute, but most of them focus on the relevant research on Confucian business culture, Hui business culture and Xiang business culture. For example, Yang Yi (2016) believes that finance and economics colleges are the cradle of cultivating businessmen. By leading students to seek and find resources from the traditional Confucian culture to promote the Confucian business culture, we can cultivate businessmen with humanistic morality, competitiveness and social responsibility. A research by Shu Yadi, Wang Qi, and Meng Fanhui (2018) on the applied general course Hui business culture for Anhui university students, due to the lack of teaching materials, has formed a self-compiled teaching content system, which can not only fit the local school running orientation of the school, but also conform to the innovation and entrepreneurship trend of the times. Liao Yi (2016) made an in-depth analysis of the practical significance of setting up the course of Xiang business culture in business Institute, and discussed how to carry out the education of Xiang business culture in three aspects: educational philosophy, curriculum and teaching methods. It can be seen that scholars have realized the necessity and feasibility of integrating traditional culture into the talent training mode of finance and economics major in higher vocational institute. Based on their research fields, they have carried out beneficial exploration respectively. However, Hui business culture and Xiang business culture are limited in case promotion due to geographical factors and cultural differences, and Qi business culture can make up for this shortcoming, which is more typical and representative.

To sum up, scholars at home and abroad are more concerned about the connotation of Qi business culture, and less about the integration with the reality of professional personnel training. The exploration of the integration of Hui business culture, Xiang business culture and financial talents training in higher vocational Institute also points out the ideas for the integration of Qi business culture. The historical status and contemporary value of Qi business culture show that the integration of Qi business culture into the talent training mode of finance and economics major in higher vocational Institute can form a nationwide teaching case, which has more research value.

\section{Rise and development of Qi business and Qi business culture \\ 3.1. Rise of Qi business and Qi business culture}

In the history of China's commercial development, Qi business and Qi business culture, represented by Jiang Taigong, are the pioneers and leaders of commercial culture. It can be said that Jiang Taigong, the founder of Qi business culture, endowed him with the spirit of pragmatism and openness.

There are many low hills and hills in Qi, and there are some small plains. Although the farmland is not as fertile as that of Lu, it is ok to plant hemp on the small plain and develop the textile industry in the mountainous areas. Under the unfavorable geographical environment and harsh natural conditions, Jiang Taigong formulated and implemented the rule method of simplifying its etiquette due to its custom. The policy of making business and industry, making fish salt benefit, the way of making ends benefit and the coincidence of female workers laid a foundation for the development of Qi. The three years of Zuozhuan Zhaogong recorded that Qi State obeys its government, and is often stronger than the princes.

In his early years, Jiang Taigong had a business experience of selling in the song of the court. After he took charge of the state of Qi, he vigorously developed commerce because of its vulgarity and simplicity, 
which fully established the pragmatic spirit of Qi business culture. Neighboring countries have made friends with Qi and used their property to do business, which fully shows that Qi's economic development has the characteristics of openness and liveliness, and forms the open essence of Qi business culture ${ }^{[1]}$.

In the Western Zhou Dynasty, under the guidance of Jiang Taigong's pragmatic and open policy, the social and economic development of Qi was relatively fast. After only two hundred and fifty years of hard work, not only the situation of "the land was scarce and the people were few" was changed, but also the handicraft industry, commerce and agriculture were greatly developed, "the figures were converged" and "Qi was a big country."

\subsection{Development of Qi business and Qi business culture}

Guan Zhong inherited Jiang Taigong's pragmatic and open spirit, and further endowed Qi business culture with the spiritual connotation of integrity, innovation, self-improvement and flexibility.

In the spring and Autumn period, the vassal states were separated and formed a situation of competing for development. Guan Zhong believes that the first thing to govern a country is to make the people rich. If the people are rich, it will be easy to govern, otherwise it will be difficult to control. Therefore, countries with good governance tend to be relatively rich, and countries with social and political chaos are often accompanied by poverty. In Guan Zhong's view, moral level and economic level complement each other. When the economic level is high, moral level will naturally improve. It is just the so-called "knowing etiquette when you are in the warehouse, knowing honor and disgrace when you have enough food and clothing," thus forming the idea of "being rich before being educated." With the help of Guan Zhong, Qi stood out in the fierce competition among powerful countries and became the first power in the spring and autumn period ${ }^{[2]}$.

After he became Duke Huan of Qi, Guan Zhong was appointed prime minister. Their general plan of governing the country continued Jiang Taigong's line of valuing commerce and actively developed industry and commerce. Guan Zhong formulated the commercial policy of low tax rate or even zero tariff, which made Qi's foreign trade prosperous and developed rapidly. Only when salt is exported to the inland countries, it will be "worth a thousand jin." Under the historical conditions at that time, Guan Zhong put forward the idea and measures of four people's separate occupation and settlement, which is not only a major reform of the national management system at that time, but also a major measure of the reform of economic division, which has epoch-making significance and role in promoting the development of production and social progress. The state promotes the exchange of skills and achievements of workers in various industries through administrative means, and controls them in the process of exchange. On this basis, on the one hand, we should control the gap between the rich and the poor, on the other hand, we should profit from it. Guan Zhong was the first politician in the world to advocate attracting investment. He proposed to reduce the collection of various taxes and charges, only $2 \%$ of the business turnover of the merchants, which was almost tax-free, so he attracted the rich merchants from other vassal states to bring a lot of wealth to the state of Qi to do business. This practice of easily seizing the wealth of an enemy country without resorting to war is a great initiative! Guan Zhong's policy of attracting investment has achieved fruitful results, making Qi the most prosperous and powerful country in a short time. Duke Huan of Qi was able to unite the nine princes and control the whole world, becoming the first overlord of the spring and autumn period. In history, Guanzhong was the first to implement the salt monopoly. Since then, the salt monopoly system has lasted for more than 2600 years, and it was only partially abolished in 2017 .

After the implementation of salt and iron official business, the state has become the most powerful commodity operator in the market, which not only prevents individual rich merchants from controlling the market, but also enables the state to obtain a large amount of income. The administrative decrees of the state have a significant impact on the price changes. Guanzi used the technique of "light and heavy" to 
conduct foreign trade. The state can regulate prices through relevant administrative decrees. For example, if the state orders the people not to sell grain, the supply of grain in the market will be insufficient and the price of grain will rise. The use of administrative decrees to intervene in prices is the concrete application and embodiment of the state's macro-control of the economy.

Openness is the biggest characteristic of the governing thought in Guan Zhong, and it is also a distinctive characteristic of Qi which is quite different from other countries in the spring and Autumn period and Warring States period. At present, the world has become a unified whole, the importance of opening up and cooperation is self-evident, and any economic entity has been deeply embedded in the global industrial chain. Therefore, in today's world trade friction is escalating, and the anti-globalization view is rampant, it is of great practical significance to study the thought of a Chinese sage 2600 years ago.

The main idea of Guanzi's theory is to strengthen the country's macro-control, gather the greatest wealth and interests for the country, and give better play to the country's macro-control through price and monetary leverage. While accumulating national strength, we should not place our hopes on other countries. Only self-reliance and hard work are fundamental. In this process, we should actively stimulate the development vitality and passion of various industries, and promote the development of productive forces to the maximum extent. The economic measures we take must proceed from reality and be determined by the time. At the same time, we should not stick to the past and be innovative, only in this way can the new normal road of China's economic development go further ${ }^{[3]}$.

Guan Zhong believes that people can't stand without trust, and businessmen can't be rich without trust. Honesty is the key to business. Reputation is one of the most important intangible assets and valuable wealth. The market economy is actually an honest economy. A dishonest businessman may cheat people for a while, but he will never succeed repeatedly. He is destined to be seen through by people and eliminated by the market. In the long-term business practice, Qi businessmen have formed a business tradition and image of honesty and trustworthiness. Wherever they go, Shandong businessmen are considered honest and reliable. This is not only the result of Qi businessmen honesty tradition and spirit inheritance from generation to generation, but also an extremely valuable spiritual wealth of Qi businessmen.

\section{Practical significance of inheriting Qi business culture}

From the social level, Qi business culture is an important part of Qi culture and an important part of Chinese excellent traditional culture. Integrating Qi business culture into the talent training of Finance and economics major in higher vocational Institute can not only carry forward the connotation and essence of Qi business culture, practice the spirit of dedication and integrity of socialist core values, but also have farreaching significance for the inheritance of Qi business culture, and regulate the business and trade behavior of the whole society.

From the industry level, finance and economics majors in higher vocational institute are skilled talents in business management, which play a guiding role in the development of enterprises in the future, and their training quality is related to the development direction of the whole industrial and commercial enterprises. The integration of Qi business culture will give consideration to knowledge, ability, quality and quality in the cultivation of talents. During the school period, the strong Qi business culture edification also helps students to continue to follow the fine tradition of Qi business culture after graduation to work, love and dedication, honest service ${ }^{[4]}$.

From the school level, the spirit of pragmatism, openness, integrity, innovation, self-improvement and flexibility emphasized by Qi business culture is also applicable to the improvement of teachers' ability and quality. Teachers are encouraged to devote themselves to school construction and development of professional ability with the spirit of dedication, pragmatism and innovation, which is of great significance to the improvement of teachers' ability and quality It is of far-reaching significance to improve teaching 
quality and promote school construction.

From the perspective of students, through the reform and upgrading of curriculum system and teaching mode, we can not only cultivate students' professional quality and ideological quality, but also play an important role in cultivating students' craftsman spirit and innovation and entrepreneurship.

\section{Integration path of Qi business culture and financial talents training in higher vocational institute}

Under the Qi business culture mode of financial professional training in higher vocational Institute, integrating Qi business culture into the training of financial professional talents in higher vocational Institute is an effective way to cultivate excellent technical and skilled talents of financial specialty, which has universal characteristics and is easy to promote. This mode integrates the excellent spiritual connotation of Qi business culture, and its main features are as follows: first, it forms a curriculum system of professional innovation integration, cultural penetration layer progressive; second, it builds a hybrid teaching mode of matrix theory and practice integration with fragmented resources (Figure 1.).

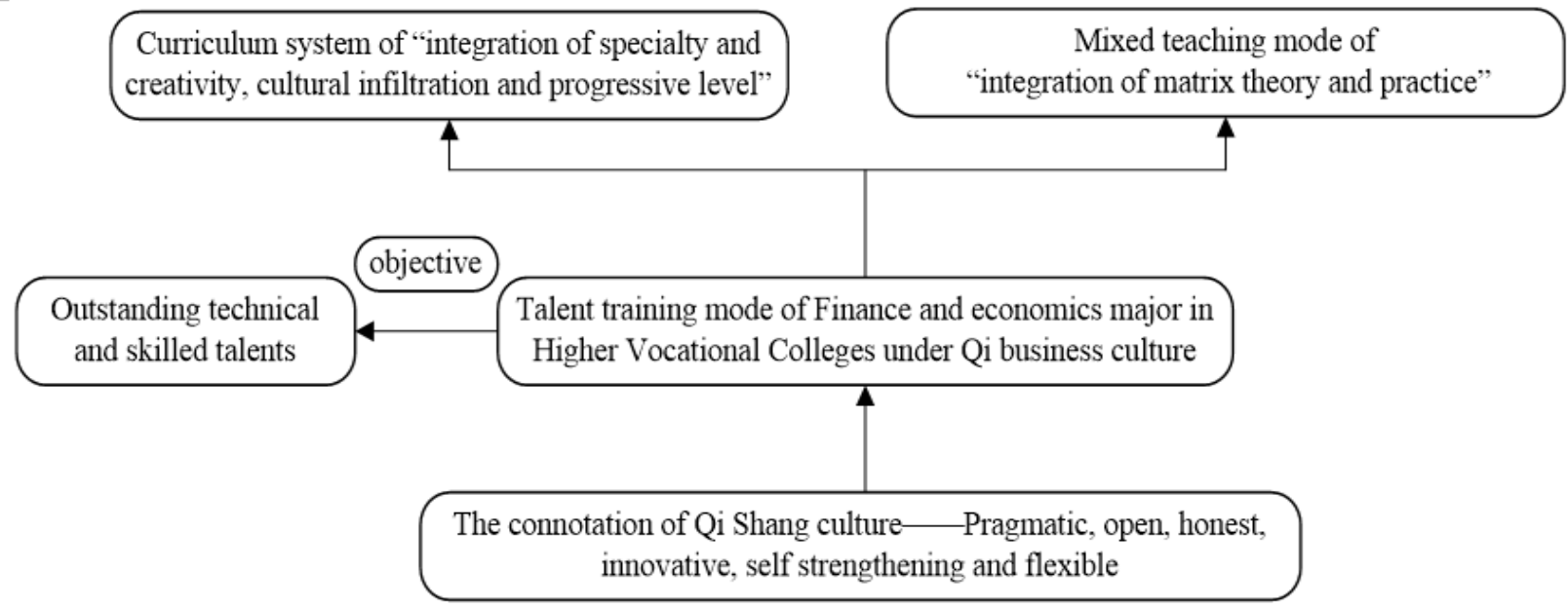

Figure 1. Talent training mode of finance and economics major in higher vocational institutes integrated with Qi business culture

\subsection{The curriculum system of the integration of specialty and creativity, the gradual infiltration of culture}

With the goal of cultivating excellent technical and skilled talents of finance and economics major, combining with professional education and innovation and entrepreneurship education, the core connotation of Qi business culture is permeated into the whole cultivation process, and the curriculum system of finance and economics major in higher vocational institute is reconstructed to form a distinctive feature of integration of specialty and innovation, progressive cultural infiltration. Among them, the curriculum system of innovation and entrepreneurship education cooperates with the curriculum system of professional education to form the basic courses of innovation and entrepreneurship, the guidance courses of innovation and entrepreneurship, the practice courses of innovation and entrepreneurship and the incubation of innovation and entrepreneurship at different levels, realizing the organic integration of professional education and innovation and entrepreneurship education ${ }^{[5]}$.

Specifically, the corresponding integration mode is established for different types of courses. For professional basic courses, Qi business culture course is set up for general education, so that students can understand Qi business culture and its spiritual connotation. For professional skills courses, we should integrate Qi business culture into professional courses to cultivate students' professionalism and professional quality. For example, the connotation of integrity in Qi business culture is consistent with the 
concept of no false accounting of accounting students, and teachers can skillfully integrate it in curriculum design. For professional development courses, with the help of innovation and entrepreneurship platform, the inheritance of Qi business culture runs through it, leading the development with culture, opening the future with innovation, and explores the new trend of Qi business culture and professional innovation integration in practice.

\subsection{Mixed teaching mode of integration of matrix theory and practice}

Qi business culture into the classroom, in the financial professional basic courses, professional skills courses and professional development courses, add Qi business culture elements, build matrix theory and practice integration hybrid teaching mode. In each professional course, nine links are designed, such as "task release," "micro lesson video," "online self-test," "teaching case," "question answering and discussion," "classroom training," "homework," "second classroom" and "learning feedback." Among them, "teaching case" is the main position for teaching to spread "Qi business culture." The part of Jiang Taigong and Guan Zhong's business thoughts which are valuable for reference today is compiled into a short story to tell the students. In the "second class" part, successful entrepreneurs or industry professors are invited to the lecture hall to introduce the struggle history of typical representatives of modern Qi business to the students, so as to cultivate excellent technical and skilled talents of finance and economics in the whole process, to achieve the purpose of inheriting Qi business culture.

\section{Conclusion}

Under the Qi business culture, the talent training mode of finance and economics major in higher vocational institute combines students' professional ability with professionalism, ideological quality and innovation and entrepreneurship by inheriting the Qi business culture, and cultivates students' excellent qualities such as pragmatism, openness, integrity, innovation, flexibility and self-improvement, so as to realize the business docking and take it as the platform, It has solved such problems as the docking of specialty construction and enterprise demand, the docking of teaching material construction and post and professional standards, the docking of teaching process and working process, the docking of teacher training and enterprise temporary training, the docking of practical training environment and business environment, and the docking of professional skills competition and enterprise post skills competition.

\section{Acknowledgments}

Thank Zibo Vocational College for the financial support of the teaching reform of vocational education.

\section{Funding}

This research was supported by the 2021 Ministry of Teaching reform of Vocational Education in ZiBo Vocational Institute and the 2020 Ministry of Special Subject of Art Education in Shandong Province.

\section{Disclosure statement}

The authors declare that there is no conflict of interest.

\section{References}

[1] Cai XY, 2020, Using Qi Culture to Promote Regional Economic Development. Financial Forum. (9): 5-8. 
[2] Chen JN, 2015, The External Dissemination of Guanzi, an Important Historical Material of Qi Culture. Journal of Sichuan Cadre Correspondence College, (9): 134-7.

[3] Dong ZC, 2017, Proceedings of the 2017 Twelve National Symposium on GuanZi, On the Characteristics of Qi Culture and the Construction of a Strong Cultural Country, 31-5.

[4] Wang Y, Zhou J, 2021, On the Intellectual Spirit of Qi Culture. Journal of Handan University, (6):4753.

[5] Yan BG, Meng DK, 2003, The Characteristics, Purpose and Essence of Qi Culture: On the Similarities and Differences of Qi, Lu and Qin Cultures. (2): 36-43. 